$\begin{array}{ll}\text { Türkiye Tarımsal Araştırmalar Dergisi } & \text { Turk J Agric Res } \\ \text { http://dergi.sirt.edu.tr } & \text { (2015) 2: 40-46 } \\ \text { TÜTAD } \\ \text { ISSN: 2148-2306 }\end{array}$

\title{
Characterization of Multifloral Honeys of Pervari Region with Different Properties
}

\author{
Mehmet Emre EREZ ${ }^{1}$, Osman KARABACAK ${ }^{2}$, Lokman KAYCI ${ }^{1 *}$, Mehmet FIDAN ${ }^{1}$, Yılmaz KAYA $^{3}$ \\ ${ }^{\text {I}}$ Siirt University, Faculty of Science and Arts, Department of Biology, Siirt, TURKEY \\ ${ }^{2}$ Gazi University, Polatl Faculty of Science and Arts, Department of Biology, Ankara, TURKEY \\ ${ }^{3}$ Siirt University, Faculty of Engineering and Architecture, Department of Computer Engineering, Siirt, TURKEY
}

\begin{tabular}{ll}
\hline Received: 02.03 .2015 & Accepted: 25.03 .2015 \\
\hline${ }^{*}$ Correspondence: kaycilokman@gmail.com &
\end{tabular}

\begin{abstract}
The quality of honey from Pervari region was almost known by all over the country in Turkey. This study was undertaken to determine (i) physico-chemical parameters, (ii) antimicrobial analysis and (iii) pollen estimation method with expert computer system obtained from three different sites of Pervari region (Siirt/Turkey). For physico-chemical parameters; moisture, free acidity, diastase activity, hydroxyl methyl furfural (HMF), invert sugar, ash, commercial glucose and proline analysis were examined. For anti-microbial analysis disc dilution method were studied on six different bacteria species. For pollen analysis; different and new expert computer system was used for comparison of pollen of plants and honey samples. The aim of the study was to evaluate the properties of multi floral honey determined from three different locations in the same region and the way to understand to which plants were visited by the bees with comparing of pollen grains of flowers and honey by using the expert computer system. Honey samples of Pervari region were of acceptable quality based on recommended criteria of Turkish Food Codex and International Honey Commission.
\end{abstract}

Keywords: Honey, physico-chemical properties, antimicrobial, pollen identification, artificial neural network

\section{Introduction}

Honey is produced by honeybees from nectar of plants and contains at least 181 substances and considered as an important part of traditional medicine (Louveaux, 1985; Sato and Miyata, 2000; Gómez-Caravaca et al., 2006). The growing interest on honey has been observed in the domain of nutrition science for several years. Total production of honey is estimated at 80.000 ton in Turkey and it is nearly $5.7 \%$ of the total honey production (Tüzen et al., 2007; Silici et al., 2007).

Pervari region has a special location for Turkey; it is in transaction region for geographical and climatic conditions with floristic diversity. Despite to approximately 150 taxa recorded by flora of Turkey, performed floristic studies which close to Pervari was indicated that more plant species were also can identify in this region (Pınar and Adigüzel, 2011).
Estimation of honey production was difficult to understand because of floristic diversity and it is significant problem for beekeepers. A pollen analysis appeared to be the most frequently used method in such identification studies (Bolchi Serini and Salvi, 1990; Bambara, 1991; Szczcesna and Rybak-Chmielewska, 1993). Pollen characterization and quantification of honeys has been the traditional method to determine the nectar sources and botanical origin, but this technique is tedious and has some limitations (Von der Ohe, 1994; Hermosin et al., 2003). Although (PO) palynological method is important for classifying, it is time-consuming, requires a very experienced analysis and is strongly dependent on the expert's ability and judgment (Piana et al., 2004).

The pollen grains have a strong coating with various three dimensional shape different from each other which allow to identify the plant species. Also pollen types in honey samples can determine for understanding the origin and the 
quality. Here, we use a consistent methodology for identification of honey origin by comparison of pollen in honey samples and plant species by using an expert system.

\section{Materials and Methods}

\subsection{Sample collection}

(i) Honey samples were obtained from three different sites in Pervari region (Site 1: Çobanören; Site 2: Balcılar; Site 3: Yanıkses) from Turkey (Figure 1). All samples were collected from different hives in a region and transferred to the laboratory and kept at $4-5{ }^{\circ} \mathrm{C}$ until analysis.

(ii) Bee samples from different hives were also taken to laboratory in a jar with $96 \%$ ethyl alcohol, for identification of bee race. For the measurement of proboscis, the head of bees were immersed in $30 \%$ alcohol. For the measurements of body parts were immersed in $70 \%$ lactic acid separately. The race of bees was identified according to their proboscis; leg, fore wing length and also the color of abdomen and thorax were also evaluated. Lengths of organelles were measured by Olympus DP50 binocular microscopy.

(iii) Flower of plant samples were collected around the hives from different localities which thought to visit by honey bees by the experience of beekeepers. The plant samples were identified and flowers were dried properly (Davis, 1988).

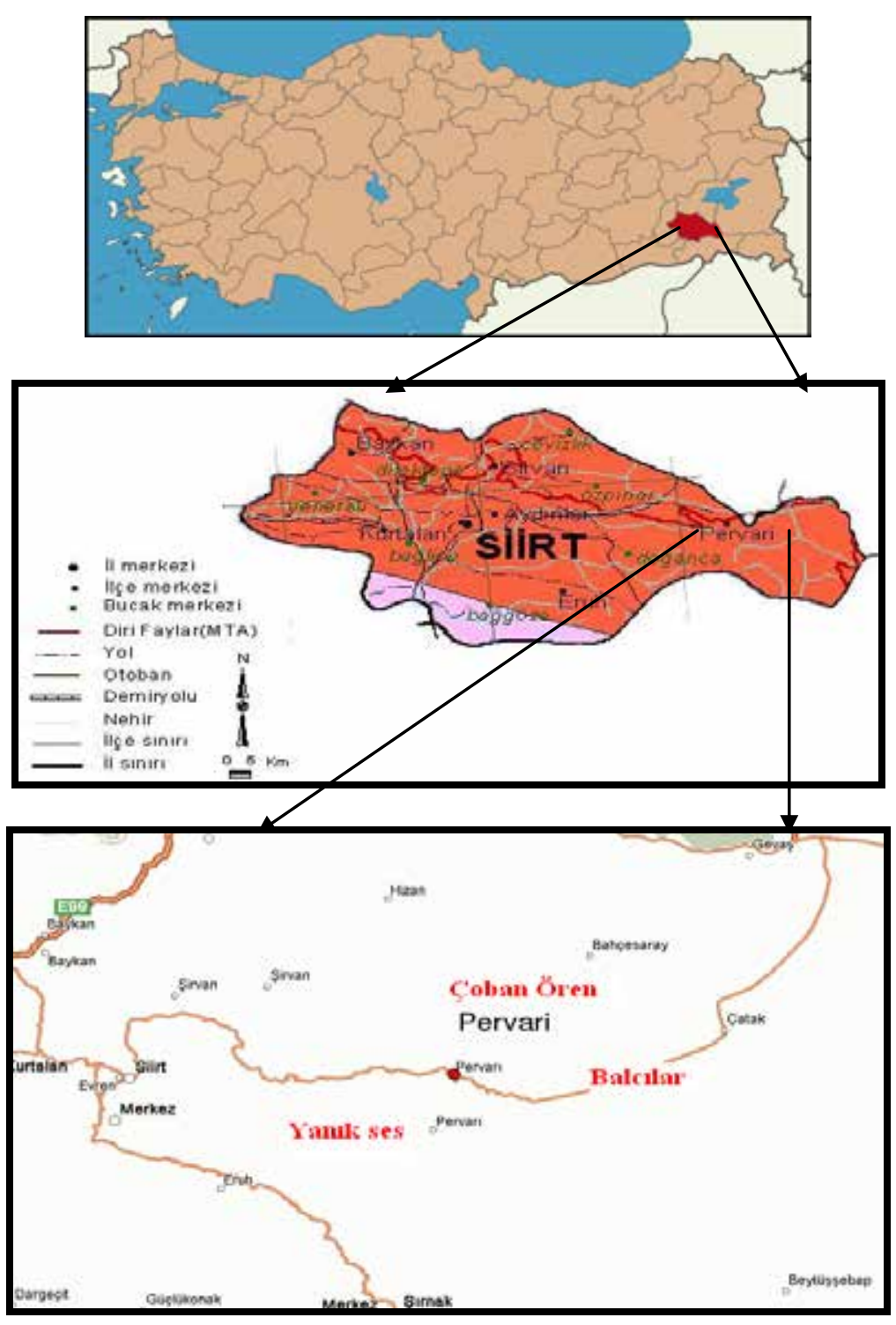

Figure 1. Location of honey sampling sites in Pervari region 


\subsection{Physicochemical and antimicrobial analysis}

The samples of honey were analyzed in triplicate according to the Anonymous (2000) and Turkish Standard Institute (TSE) standards. Water content (moisture) was determined by an Abbetype refractometer reading at $20^{\circ} \mathrm{C}$, according to the relationship between honey water content and refractive index of samples (Bogdanov et al., 2004).

Ash, proline contents and electrical conductivity were determined by the methods of Bogdanov et al. (1997). Ash content was determined by heating $5 \mathrm{~g}$ of honey at $625{ }^{\circ} \mathrm{C}$ in a muffle furnace. Proline content was determined by the measurement of the absorbance at $510 \mathrm{~nm}$ of the resulting product between proline and ninhydrin in an acidic medium. Electrical conductivity was measured in a $20 \%$ (w/v) solution of honey in deionized water with low electrical conductivity by using conductivity meter. Hydroxy methyl furfural (HMF) content was calculated according to method. No: 980.23.

The $\mathrm{pH}$ was assessed in a $10 \%(\mathrm{w} / \mathrm{v})$ solution of honey in distilled water by mean of $\mathrm{pH}$ meter. Free acidity was determined using the titrimetric method: acid components were neutralized with a standard solution of sodium hydroxide in aqueous honey solution ( $10 \mathrm{~g}$ in $75 \mathrm{~mL}$ distilled water).

Invert sugar content and diastase were analyzed according to TSE 3036, commercial glucose according to Anonymous (2000). Sugar content was determined by High Performance Liquid Chromatography (HPLC) with refractive index (RI) detector and analytical stainless-steel column in polar amino propylsilane $\left(-\mathrm{NH}_{2}\right)$. In a $100 \mathrm{ml}$ volumetric flask, containing $25 \mathrm{ml}$ of methanol, 5 $\mathrm{g}$ of honey dissolved in water were transferred and filled up with water. The solution was filtered through a $0.45 \mathrm{ml}$ syringe filter (Bogdanov et al., 1997).
The antimicrobial activity of honey samples was studied using six bacterial strains. Disc diffusion method was performed for antimicrobial analysis.

\subsection{Pollen analysis}

Prepared pollen slides for each plant were analyzed by using the technique of Wodehouse (1935). This material was used to prepare slides by using glycerin-jelly mixed with $1 \%$ Safranin. The prepared slides were photographed under the Olympus CX31 light microscope using oil immersion (Figure 2). Also pollen slides from honey samples were performed by according to Louveaux et al. (1978). Honey samples were homogenized with sterile baguette and heated until $45-50{ }^{\circ} \mathrm{C}$. Samples were centrifuge at $3500 \mathrm{rpm}$, the supernatant was removed and the residue was taken with sterile needle to glycerin-jelly mixed with 1\% Safranin (Figure 3).

The pollen analysis of this study was different from routinely performed pollen analysis methods. The pollen samples of plants and the honey were compared with each other by vision and machine learning system. For this purpose part algorithm technique was used for the estimation. Part algorithm is known as the combination of C4.5 decision tree and training algorithm RIPPER (Cohen, 1995). The block diagram pertaining to the model used in this study was shown in Figure 4.

The study consists of five blocks. The processes in these blocks can be summarized as;

Block 1: Obtaining of images belonging to the different positions of selected pollens for plant species and honey.

Block 2: Obtaining contrast, correlation, entropy, energy and homogeneity of pollen textures with GLCM.

Block 3: 40 pollen images from plants were

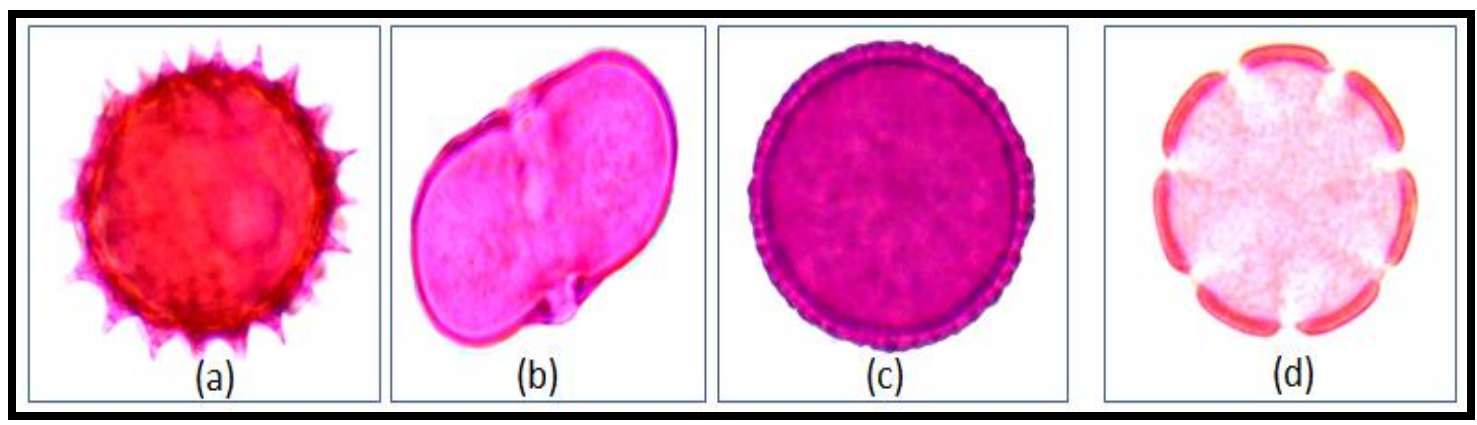

Figure 2. The pollen grains from selected plants. (a) Gundelia tournefortii, (b) Anchusa azurea, (c) Daphnea mucronota, (d) Asperula xylorrhiza 
considered as training set and 40 pollen images from honey were considered as test set. The aim of these sets is to compare pollen from honey with pollen of plant species.

Block 4: Classification of training-test partitions through PART algorithms.

Block 5: Presentation of classification results (decision stage).

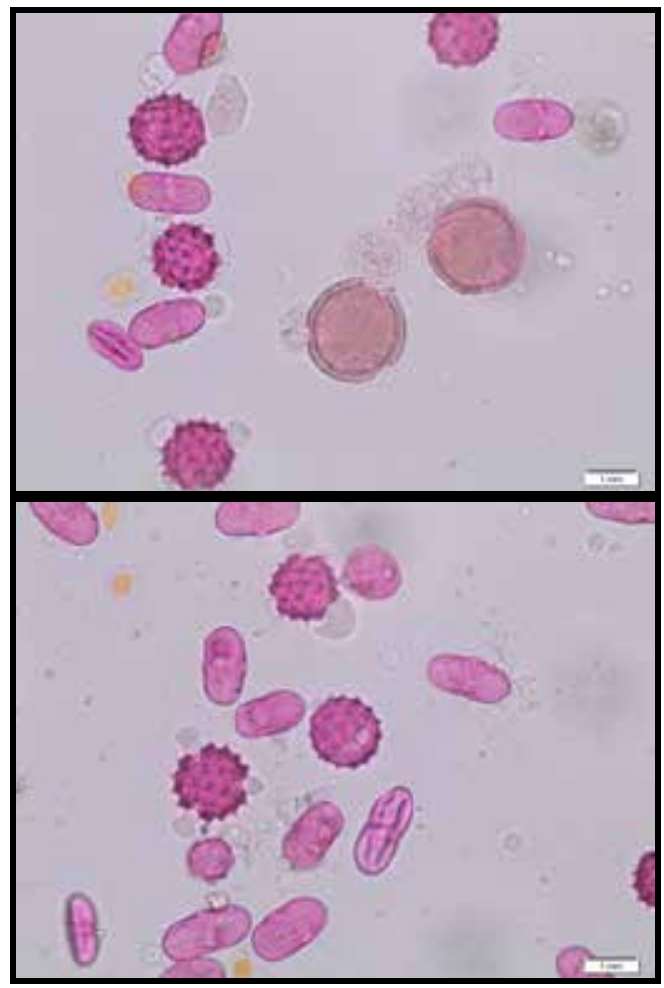

Figure 3. The pollen grains from honey samples

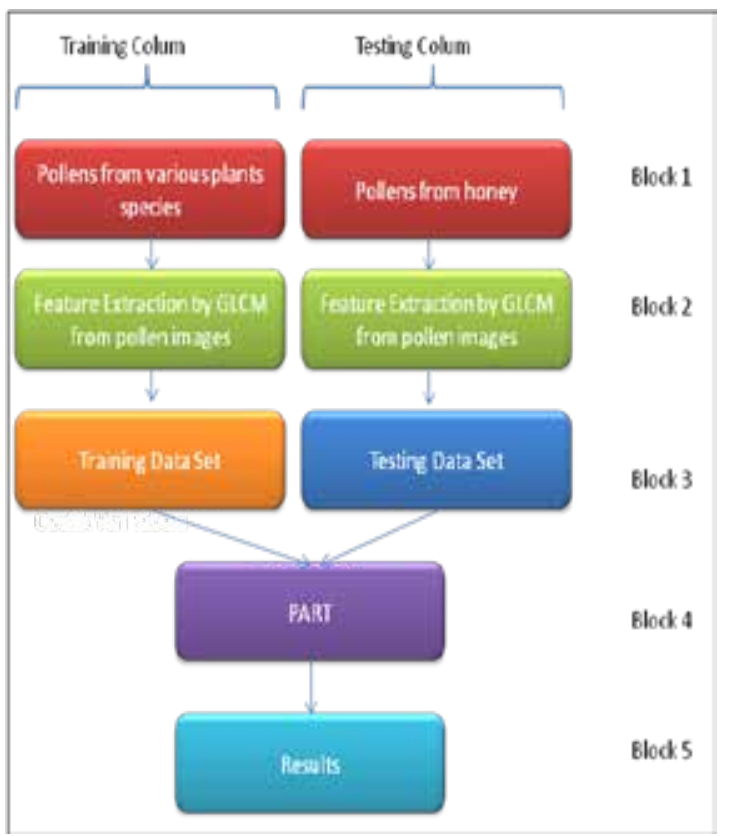

Figure 4. Proposed method for pollen identification

\subsection{Statistic analysis}

The data reported are averages of triplicate observations. The data were subjected to statistical analysis using Minitab statistical software (Statistical analysis to compare the physicochemical analysis Multiple Analysis of Variance (MANOVA) was performed.

\section{Results and Discussion}

The means of physico-chemical analysis and the sugar content obtained from honey samples are presented in Table 1. Moisture of honey sample is the quality criterion that determines the capability of honey to remain stable and to resist spoilage by yeast fermentation (Singh and Bath, 1997). The water content depends on the climatic conditions during the season, the level of the maturity reached in the hive, the processing techniques and the storage conditions (Bogdanov et al., 2004). In this study all investigated honey samples were in acceptable ranges. The moisture content of samples was detected in range of 12.58-15.99 and these differences may be due to content of original plant and climatic conditions.

Free acidity of honey can be differ by botanical types of region. Honey samples characterized by the lowest average; free acidity were studied by acacia honey samples, with mean value of 11.6 meq $\mathrm{kg}^{-1}$, compared with sunflower honey samples with mean value of $27.2 \mathrm{meq} \mathrm{kg}{ }^{-1}$ (Lazarević et al., 2012). Also in our study free acidity value varies from 16.41 to 26.20 according to their botanical origin. Similar results were detected by Yilmaz and Küfrevioğlu (2000). All investigated samples met the requirement which requires that the acidity should not be exceeding 50.0 meq $\mathrm{kg}^{-1}$ (Anonymous, 2002).

Minerals are introduced into honey primarily with pollen. Also mineral contents are depends on the predominant pollen present in honey. Electrical conductivity is also depends on the mineral, organic acid and protein content of honey. Therefore, electric conductivity is a parameter which is often used in routine honey quality control, and can be considered a valid criterion for determining the botanical origin of a honey sample (Bogdanov et al., 2004). Electrical conductivity in investigated honey samples showed some variation depending on their botanical origin and pollen distributions. The lowest mean values for electrical conductivity were obtained for the Yanıkses honey samples $\left(0.15 \mathrm{mS} \mathrm{cm} \mathrm{cm}^{-1}\right)$, and the highest mean value for electrical conductivity was measured in Çobanören honey $\left(0.32 \mathrm{mS} \mathrm{cm}^{-1}\right)$. 
Table 1. The results of physico-chemical analysis of flower honey samples

\begin{tabular}{|c|c|c|c|c|}
\hline Parameters & $\begin{array}{c}\text { Site 1 } \\
\text { (Yan1kses) }\end{array}$ & $\begin{array}{c}\text { Site } 2 \\
\text { (Balc1lar) }\end{array}$ & $\begin{array}{c}\text { Site } 3 \\
\text { (Çobanören) }\end{array}$ & Satisfactory limit by EU \\
\hline Moisture (\%) & $14.90 \pm 0.21$ & $12.58 \pm 0.15$ & $15.99 \pm 0.32$ & At most 20 \\
\hline Free acidity (meq kg-1) & $20.30 \pm 0.39$ & $16.41 \pm 0.42$ & $26.20 \pm 0.31$ & At most 50 \\
\hline Electrical conductivity $\left(\mathrm{mS} \mathrm{cm}^{-1}\right)$ & $0.1584 \pm 0.012$ & $0.1659 \pm 0.016$ & $0.2901 \pm 0.019$ & At most 1.52 \\
\hline Diastase activity $(\%)$ & $8.3 \pm 2.6$ & $8.3 \pm 2.6$ & $10.9 \pm 2.6$ & At least 8 \\
\hline Invert sugar $(\%)$ & $71.65 \pm 1.2$ & $69.18 \pm 2.85$ & $66.96 \pm 3.1$ & At least 60 \\
\hline $\mathrm{HMF}\left(\mathrm{mg} \mathrm{kg}^{-1}\right)$ & $17.149 \pm 3.84$ & $15.993 \pm 2.91$ & $19.123 \pm 3.65$ & At most 40 \\
\hline Ash $(\%)$ & $0.4201 \pm 0.03$ & $0.3696 \pm 0.0 .2$ & $0.4379 \pm 0.0 .3$ & At most 0.6 \\
\hline Proline $\left(\mathrm{mg} \mathrm{kg}^{-1}\right)$ & $220 \pm 5.8$ & $192 \pm 6.4$ & $234 \pm 5.9$ & At least 180 \\
\hline Commercial glucose & ND & ND & ND & Not be found \\
\hline
\end{tabular}

ND: Not detected

The diastase activity and HMF content are widely recognized parameters in evaluating the freshness of honey (Sancho et al., 1992). Honey samples showed an appropriate diastase number ranging from 8.3 to 10.9 . HMF content, has maximum value of $19.12 \mathrm{mg} \mathrm{kg}^{-1}$. The variation in the activity of diastases and HMF may be related to source of honey as well as climate of region (Singh and Bath, 1997).

Ash content is one of these parameters that have been associated with botanical and geographical origins of honey samples. The ash content in honey is generally small and depends on nectar composition of predominant plants in their formation (Al-Khalifa and Al-Arify, 1999). In our study, ash content of samples (mean $0.40 \%$ ) was in the acceptable range.

The content of fructose and glucose in honey varies from honey to honey. Generally, the fructose ranges from $30-44 \%$ and glucose from $25-$ $40 \%$. The balance of these two major sugars is the main reason that leads to crystallization of honey, and the relative percentage of each determines whether it crystallizes rapidly or slowly. The speed of honey to crystallize depends not only on its composition, but also on the presence of catalysts, like seed crystals, pollen grains and pieces of beeswax in the honey. The amounts of fructose and glucose vary from $36 \%$ and $29 \%$ in investigated honey samples (Table 2). The fructose/glucose ratios were widely distributed $(0.93 \pm 1.56)$, these indicate the variety of floral sources, where the honey samples were originated. The proportion of sucrose is similar to that found by Mohamed et al. (1982) and Abu-Tarboush et al. (1993).
Osmolarity, acidity, hydrogen peroxide, phenolic compounds and volatile compounds are affect the antimicrobial activity of honey samples (Molan, 1992). Due to the presence of such compounds in investigated multifloral honey samples by the composition of plant resources had shown different antibacterial properties against to six different bacteria (Table 3). Silici et al. (2010) have shown that there can be a large variation in the antimicrobial activity of different honey samples from the same plant sources.

Bee samples were taken from every hives for the race identification. The race of bees was Apis mellifera caucasica Gorbachev with $6.98 \mathrm{~mm}$ tongue length. Totally 60 different plant species belonging to different 17 family were collected and identified. Selection of plant species were made by the experience of the beekeepers. The botanical families Asteracea, Apiaceae, Lamiaceae, Malvaceae, Rosaceae and Thymelaeaceae were most frequently found in honey samples. The specific features of pollen grains provide some information about which family or even which genus they belong. Rapid and accurate identification of pollen potential will be helpful for identification of botanical origin of honey. Potentially; it can also be more attractive for testing of honey by agencies involved in detecting fraudulent labeling.

Part algorithms technique was applied to images of the pollen from selected plant species and the honey samples obtained with the same procedures. Pollen database of plant species were compared with the pollen in honey. As a result of this study, identification and classification of pollen type by using the Part algorithm was indicate a significant success as $78 \%$.

Table 2. The sugar content of honey samples (gr 100gr $\left.{ }^{-1}\right)$

\begin{tabular}{lccccc}
\hline Sites & Fructose & Glucose & Saccarose & Maltose & Fructose/glucose \\
\hline Site 1 (Yanıkses) & $37.3 \pm 3.4$ & $28.2 \pm 2.5$ & $<0.9$ & $<1.2$ & 1.32 \\
Site 2 (Balc1lar) & $36.9 \pm 3.3$ & $29.0 \pm 2.6$ & $<0.9$ & $<1.2$ & 1.27 \\
Site 3 (Çobanören) & $36.1 \pm 3.3$ & $30.4 \pm 2.7$ & $<0.9$ & $<1.2$ & 1.19 \\
\hline
\end{tabular}


Table 3. Antibacterial effects of honey samples on selected bacteria strains

\begin{tabular}{lccc}
\hline Bacteria & $\begin{array}{c}\text { Site 1 } \\
\text { (Yanıkes) }\end{array}$ & $\begin{array}{c}\text { Site 2 } \\
\text { (Balc1lar) }\end{array}$ & $\begin{array}{c}\text { Site 3 } \\
\text { (Çobanören) }\end{array}$ \\
\hline Escherichia coli & + & + & + \\
Bacillus subtilis & + & + & - \\
Pseudomonas & - & - & - \\
aueriginosa & & & - \\
Bacillus cereus & + & + & + \\
Staphylococcus & + & + & - \\
$\begin{array}{l}\text { aereus } \\
\text { Streptococcus }\end{array}$ & - & - & \\
pyogenes & & & \\
\hline
\end{tabular}

\section{Conclusions}

In conclusion, the physicochemical characteristics of the honey samples were generally agreed with national and international honey standards. Despite to similar region sampling, differences between the findings obtained from several studies and our findings may be caused to differences in geographical, climatic conditions and biodiversity.

Honey samples physico-chemical properties vary from region to region, and can be used to assess the quality. However they don't provide any information about the origin of honey and where it is' produced. In multi-floral honey samples, we currently have to use palynological characteristics to identify the origin and a rapid and accurate automated technique may solve the problem for beekeepers and food monitoring agencies in having correct labels on honey sold commercially. Therefore rapid and accurate identification of pollens of species are an important criterion for the botanical origin of honey samples and it can be performed only by interdisciplinary studies.

\section{Acknowledgement}

This work has been supported by the DİKA No. 2011/DFD/01. The authors wish to thank to "The Association of the Beekeeping Organization of Siirt" for providing the honey samples.

\section{References}

Abu-Tarboush, H.M., Al-Kahtani, H.A., El-Sarrage, M.S., 1993. Floral types identification and quality evaluation of some honey types. Food Chemistry, 46: 13-17.

Al-Khalifa, A.S., Al-Arify, I.A., 1999. Physicochemical characteristics and pollen spectrum of some Saudi honeys. Food Chemistry, 67: 21-25.

Anonymous, 2000. Association of Analytical Communities (AOAC). Official Methods of Analysis (17th ed.). Washington, DC: Association of Official Analytical Chemists.
Anonymous, 2002. The Council of the European Union. Council Directive 2001/110/EC of 20 December 2001 Relating to Honey. Official Journal of the European Communities, 1(10): 47-52.

Bambara, S.B., 1991. Using pollen to identify honey. American Bee Journal, 131(4): 242-243.

Bogdanov, S., Martin, P., Lullmann, C., 1997. Harmonized methods of the European Honey Commission. Apidologie, 28: 1-59.

Bogdanov, S., Ruoff, K., Persano Oddo, L., 2004. Physico-chemical methods for the characterisation of unifloral honeys: A review. Apidologie, 35: 4-17.

Bolchi Serini, G., Salvi, G., 1990. I mieli Lombardi: Rizultati di analisi palinologiche. Ape Nostra Amica, 12(1): 6-9.

Cohen, W.W., 1995. Fast effective rule induction. In: Machine Learning: Proceedings of the Twelfth International Conference. Lake Tahoe CaliforniaMorgan, pp. 115-123.

Davis, P.H., 1988. Flora of Turkey and The East Aegean Islands. Suppl., Vol. 10, Edinburgh University Press, Edinburgh.

Gómez-Caravaca, A.M., Gómez-Romero, M., ArráezRomán, D., Segura-Carretero, A., FernándezGutiérrez, A., 2006. Advances in the analysis of phenolic compounds in products derived from bees. Journal of Pharmaceutical and Biomedical Analysis, 41: 1220-1234.

Hermosin, I., Chicon, R.M., Dolores Cabezudo, M., 2003. Free amino acid composition and botanical origin of honey. Food Chemistry, 83: 263-268.

Lazarević, K.B., Andrić, F., Trifković, J., Tešić, Z., Milojković-Opsenica, D., 2012. Characterisation of Serbian unifloral honeys according to their physicochemical parameters. Food Chemistry, 132: 2060-2064.

Louveaux, J., 1985. Les produits du rucher. In: Les abeilles et leur élevage, Edition Opida, pp.. 165-199.

Louveaux, J., Maurizio, A., Vorwohl, G., 1978. International Commission for bee botany of IUBS, Methods of Melissopalinoloji. Bee World, 59: 139157.

Mohamed, M.A., Ahmed, A.A., Mazid, M.M., 1982. Studies on Libyan honeys. Journal of Food Quality, 4: $185-201$

Molan, P.C., 1992. The antibacterial activity of honey. 1. The nature of the antibacterial activity. Bee World, 73(1): 5-28.

Pınar, S.M., Adıgüzel, N., 2011. Flora of an important plant area: Çatak Valley-II (Çatak-Van/Turkey). Biological Diversity and Conservation, 4(2): 99-124.

Piana, L., Oddo, L.P., Bentabol, A., Bruneau, E., Bogdanov, S., Declerck, C.G., 2004. Sensory analysis applied to honey: State of the art. Apidologie, 35: 26-37.

Sancho, M.T., Muniateugi, S., Hudiboro, J.F., Simal, J.F., 1992. Aging of honey. Journal of Agricuture and Food Chemistry, 40: 134-138. 
Sato, T., Miyata, G., 2000. The nutraceutical benefit, part II: Honey. Nutrition, 16: 468-469.

Silici, S., Ünlü, M., Vardar, G., 2007. Antibacterial activity and phytochemical evidence for the plant origin of Turkish propolis from different regions. World Journal of Microbiology and Biotechnology, 23(12): 1797-1803.

Silici, S., Sağdiç, O., Ekici, L., 2010. Total phenolic content, antiradical, antioxidant and antimicrobial activities of Rhododendron honeys. Food Chemistry, 121: 238-243.

Singh, N., Bath, P.K., 1997. Quality evaluation of different types of Indian honey. Food Chemistry, 58(1-2): 129-133.

Szczcesna, T., Rybak-Chmielewska, H., 1993. Analiza py kowa miodo'w (przeglc, cad literatury), Pszczelarstwo, 5: 10-11.

Tüzen, M., Silici, S., Mendil, D., Soylak, M., 2007. Trace element levels in honeys from different regions of Turkey. Food Chemistry, 103: 325-330.

Von der Ohe, W., 1994. Unifloral honeys: Chemical conversion and pollen reduction. Grana, 33: 292294.

Wodehouse, R.P., 1935. Pollen Grains. Hafner Publishing Company, New York.

Yılmaz, H., Küfrevioğlu, İ., 2000. Composition of honeys collected from Eastern and South-Eastern Anatolia and effect of storage on hydroxyl methyl furfural content and diastase activity. Turkish Journal of Agriculture and Forestry, 25: 347-349. 